\title{
EL SUEÑO DE LA «RESTAURACIÓN» REPUBLICANA
}

JOSÉ PEÑA GONZÁLEZ 
SUMARIO

1. INTRODUCCIÓN. 2. LEGALIDAD Y LEGITIMIDAD INSTITUCIONAL.3. EL CISMA DEL EXILIO. 4. LA COYUNTURA INTERNACIONAL. 5. DE AZAÑA A MALDONADO. 6. RECUPERACIÓN DEMOCRÁTICA Y RESTAURACIÓN.... MONÁRQUICA. 


\title{
EL SUEÑO DE LA «RESTAURACIÓN» REPUBLICANA
}

\author{
POR \\ JOSÉ PEÑA GONZÁLEZ \\ Catedrático de Derecho Constitucional Universidad CEU San Pablo
}

\section{INTRODUCCIÓN}

Advertía Juan Marichal en los años noventa que «la historia de la España posbélica (1939-1975) no puede escribirse sin prestar atención a la España del exilio. Porque la historia política del exilio español no es una historia entre anecdótica y patética de una comunidad humana más de gentes desplazadas, temporalmente, de su morada natural: en suma, la historia política del exilio español, es, sencillamente, historia de España». ${ }^{1}$

Destacaba Marichal en el Prólogo de la obra de Alted, al que corresponde la anterior cita, que el exilio republicano fue «una expatriación perseverante, con un norte constante: la restauración de la convivencia democrática moderna en España». Y no se equivocaba el profesor de Harvard, porque el final de esa expatriación forzosa coincide en el tiempo con lo que Marías llamaba «la devolución de España a los españoles» tras la muerte de Franco y el inicio del cambio democrático en nuestra Patria. Pero en ese tránsito hacia la legalidad democrática jugó un papel importante la renuncia del Presidente Maldonado y del último Jefe del Gobierno Republicano en el exilio, disolviendo las instituciones repu-

\footnotetext{
${ }^{1}$ Alted, Alicia: «El archivo de la II República Española en el exilio, 1945-1977. Inventario del Fondo Paris». F.U.E. Madrid, 1993. Prólogo de Juan Marichal. La cita en Pág. 11.
} 
blicanas en el año 1977, una vez celebradas las elecciones democrática del 15 de junio, y vista la voluntad democratizadora puesta en marcha por la Corona. ${ }^{2}$

Nota característica de esas cuatro décadas fue la voluntad de los dirigentes republicanos de mantener la legalidad y legitimidad de este régimen en el difícil exilio. Se vive en una especie de «empacho de legalidad» que se inicia en la última reunión de Cortes en territorio español en 1939, «sesión de Cortes histórica y dramática», en acertada expresión de José Maria del Valle ${ }^{3}$, y se mantendrá hasta la disolución institucional de $1977 .{ }^{4}$

La reunión del castillo de Figueras fue una prueba más de la voluntad de representar la legalidad republicana en una tesitura casi lindante con la exageración. Hoy cuesta trabajo imaginar el formalismo seguido por los altos dignatarios de la II República, cuando las tropas de Franco están pisándole los talones, y tanto el Presidente de la República como el de las Cortes y el Gobierno están asumiendo sus compromisos constitucionales de forma impecable. Martínez Barrio preside la última sesión de Cortes Republicanas celebrada en territorio nacional, y ante ellas Juan Negrín hace pública una Declaración Ministerial sobre la situación que es aprobada por las Cortes cuyos miembros reiteran la confianza al Jefe del Gobierno5.

El día 6 de febrero de 1939 el Presidente Azaña, junto con el de las Cortes, y los Presidentes Autonómicos Companys y Aguirre cruzan la frontera. Inmediatamente después, y por separado- también aquí se guardan las formas de manera exquisita-, lo harán Negrín y el Gobierno republicano. ${ }^{6}$ Se está iniciando un larguísimo exilio- el más largo habido en Europa tras el de los rusos blancos tras 1917-, pero del que hay prueba documental de todas sus actuaciones por el prurito legalista de dejar constancia de ello para conocimiento de las generaciones sucesivas y en la secreta ilusión de que un día la República volvería a España y habría que contar con la documentación necesaria para una dación de cuentas. Ello explica el fondo docu-

\footnotetext{
${ }^{2}$ La Declaración conjunta de ambas instituciones republicanas- Jefatura del Estado y Presidencia del Gobierno- tuvo lugar el 21 de junio de 1977. El «Mensaje de despedida» está fechado en París el $1^{\circ}$ de julio de 1977. Vease, entre otros, Cabeza Sánchez Albornoz, Sonsoles: «Historia política de la II República en el exilio». F.U.E. Madrid, 1997. Pág. 407 y n.p.p. no 78 y 79.

${ }^{3}$ Valle, José Maria: «Las Instituciones de la República Española en el exilio». Ruedo Ibérico. Paris, 1976. Pág. 14.

${ }^{4}$ La última vez que se reúnen las Cortes Republicanas en España tuvo lugar en el Castillo de Figueras el 1 de febrero de 1939, levantándose la sesión a las 12.45 de la noche.

${ }^{5}$ Negrín anuncia «la inminente derrota» del ejercito republicano. Véase Cabeza, Sonsoles. Op. Cit. Pág. 9

${ }^{6}$ Los diputados republicanos abandonan Figueras con dirección a Francia cada uno cuando puede y como puede. Negrín regresa a España a los cuatro días pidiéndole a D. Manuel Azaña que volviera a la zona centro para levantar la moral de los combatientes. El Presidente rehusó.
} 
mental que Maldonado, el último Presidente de la República en el exilio, en el año 1979 entrega a Don Pedro Sainz Rodríguez, Patrono y Director de la Fundación Universitaria Española (F.U.E), conteniendo el Archivo de la República Española en el exilio. ${ }^{7}$ Es digno de destacarse la caballerosa conducta de dos políticos que militaban en campos antagónicos. Sainz Rodríguez era monárquico juanista mientras Maldonado representaba la máxima autoridad republicana en el exilio. ${ }^{8}$

\section{LEGALIDAD Y LEGITIMIDAD INSTITUCIONAL}

He calificado de empacho de legalidad la conducta seguida por los líderes republicanos en el exilio, y creo que no exagero. Llevaron los formalismos al extremo, como si estuvieran viviendo en condiciones de normalidad política constitucional. El problema era que bajo un mismo fondo de legalidad, la Constitución Republicana de 1931, coexistían dos legitimidades diferentes y hasta 1945 encontradas. De un lado la Diputación Permanente como suprema representación de la soberanía nacional que ostentaban las Cortes, y de otra el Gobierno republicano?. A ello hay que añadir las diferencias personales entre sus dirigentes. Prieto junto con los restos del largocaballerismo y el besteirismo, mas la UGT y Martínez Barrio se alineaban contra Negrín, apoyado por sus fieles y el PCE. Por si faltaba poco había un trasfondo de contenido económico sobre la administración de los bienes del estado republicano tras su derrota.

Azaña, desde Francia, presenta su dimisión el día 27 de febrero de 1939, justamente en el día que se cumple el décimo aniversario de su boda con Doña Lola de Rivas Cherif. Al principio se instala en la Embajada española en París que dirige un conocido negrinista: el Doctor Pascua. ${ }^{10}$ Después marcha a Collonges-

\footnotetext{
${ }^{7}$ El citado archivo estaba repartido en tres fondos de distinta entidad y número de documentos. El llamado Fondo Chile constaba de 45 cajas. El Fondo México 142 y el Fondo París 1033 cajas. Véase Vicenta Cortes Alonso, Archivera del Estado, en Alted: Op. Cit. Pág. 18. El llamado Fondo París ha sido inventariado por la profesora Alted constituyendo la base de la obra referenciada.

${ }^{8}$ Curiosamente ambos sufrieron el exilio durante el franquismo. Don Pedro no volvió a España hasta el año 1969 y Maldonado hasta el 20 de noviembre de 1979, dándose la coincidencia que fuera en el cuarto aniversario del fallecimiento de Franco.

${ }^{9}$ La superioridad, al menos teórica del legislativo venía consagrada en el Art.51. La Diputación Permanente es elegida por el Congreso (Art. 62) y el Gobierno viene regulado en el Título VI (Arts. 86-93). A la Presidencia de la República consagra el Título V (Arts. 67-85)

${ }^{10}$ La relación detallada de todo lo sucedido desde su salida de España hasta el momento de la dimisión en la carta que Azaña dirige a D. Ángel Ossorio fechada en Collonges-sous- Saleve el 28 de junio de 1939. Véase Azaña: OO.CC. Ed. de Juan Marichal. Ed. Oasis. México, 1966-68. Tomo III, Págs. 535-554.
} 
sous- Saléve desde donde remite la carta de dimisión al Embajador Pacua para que la haga llegar al Presidente de las Cortes, Don Diego Martínez Barrio, instalado en París. ${ }^{11}$ También lo comunica por telegrama a Don José Giral. ${ }^{12}$ La dimisión la acelera el reconocimiento por parte de Francia e Inglaterra del gobierno de Burgos. ${ }^{13}$ Azaña también sigue a rajatabla el procedimiento constitucional previsto para el caso en el Art. 74 de la Constitución de $1931 .{ }^{14}$ Se abre la presidencia provisional de la República española en el exilio en la persona de Martínez Barrio. Esta interinidad dura hasta el 10 de enero de 1945 fecha en la que Martínez Barrio convoca Cortes en Méjico. ${ }^{15}$ Hay que tener en cuenta que Don Diego había ocupado ya interinamente la Presidencia de la República tras la destitución de Alcalá Zamora en la sesión del día 7 de abril de 1936, siguiendo el mandato constitucional. Como señala José Maria del Valle, se vive «una exacerbación de escrúpulos legalistas», hasta el punto que se prohíbe el voto por correo, tal como disponía el Reglamento de la Cámara. ${ }^{16}$ Los socialistas se oponen a esta convocatoria alegando que no había el quórum establecido en el Reglamento, por lo que solicitan que en lugar de reunión de Cortes se convoque una «Junta de Diputados». La minoría socialista aduce también que el mandato de los diputados elegidos tras las elecciones del 16 de febrero de 1936, duraba solo cuatro años, por lo que estaba agotado. Añaden que de acuerdo con la legalidad republicana no pueden celebrarse reuniones de Cortes fuera del territorio nacional. A pesar de ello y gracias a la decisión del Presidente Ávila de declarar la extraterritorialidad del Club de France, la sesión tiene lugar el día 10 de enero, en lo que Sonsoles Cabeza califica muy acertadamente de «sesión necrologica» ${ }^{17}$. Tras este legalismo difícil de entender en la situación de exiliados en que se encontraban los diputados re-

\footnotetext{
${ }^{11}$ En el no 89 de la Avenue Neuilly, $4^{\circ}$. París

${ }^{12}$ Tambien exiliado en París en 6 rue du Chatillon-4-gauche. París XVI.

${ }^{13}$ La carta de dimisión en OO.CC. Op.Cit. Tomo II. Pág. 567.

${ }^{14}$ La Diputación Permanente de las Cortes republicanas tiene su sede en París en un local alquilado en la rue de la Pepiniere. Allí se reúnen el día 3 de marzo de 1939, convocadas por Martínez Barrio, dándose por enteradas de la dimisión de Azaña. Por votación unánime eligen Presidente Provisional de la República al político sevillano. Reunidas de nuevo el 31 de marzo, celebran una sesión tumultuosa con fuerte discusión entre Negrín y Martínez Barrio. En la misma la Pasionaria interviene a favor de Negrín y en contra de Martínez Barrio con un discurso muy agresivo frente al Presidente de las Cortes y provisionalmente de la República.

${ }^{15}$ Autorizadas por el Presidente mejicano Ávila Camacho quien declara transitoriamente la extraterritorialidad del «Club France» para que se puedan celebrar las sesiones de Cortes. Asisten 72 diputados y se adhieren 49 establecidos en otros países. Igualmente se da lectura a los 172 diputados fallecidos desde julio de 1939.

${ }^{16}$ Op. Cit. Pág. 87

${ }^{17}$ Op. Cit. Pág. 37
} 
publicanos, sobrevolaban las diferencias entre Prieto y Negrín, amen del deseo de ambos dirigentes por controlar los bienes de la República en el exilio.

Tras la sesión necrológica, se reúne por segunda vez el parlamento republicano en el exilio el día 17 de agosto de 1945, en el Palacio de los Consejos de México, también declarado provisionalmente por el Presidente Ávila como territorio español en base a la declaración de extraterritorialidad. ${ }^{18}$ Preside el diputado Fernández Clérigo $^{19}$ y en ella Martínez Barrio asume la presidencia interina de la República, aceptando la dimisión del Gobierno Negrín, quien hasta la fecha se ha negado a presentarla aduciendo que solo podía hacerlo ante el Presidente de la Republica ${ }^{20}$. Martínez Barrio, votado por 96 diputados, otorga la promesa de fidelidad a la República y la Constitución, que le pide Fernández Clérigo en su condición de Vicepresidente $2^{\circ}$ de la Cámara y es designado Presidente Provisional de la II República Española. ${ }^{21}$ A continuación Negrín presenta la dimisión el mismo día 17 de agosto al nuevo Presidente de la República. Este encarga formar gobierno a D. José Giral. Se abre una etapa de treinta y un años en los cuales se designarán tres Presidentes de la República ${ }^{22}$ y siete Jefes del Gobierno ${ }^{23}$.

En febrero de 1946 el Gobierno republicano se instala en París. El Presidente de la República, Diego Martínez Barrio, llega a la capital de Francia el 12 de marzo de $1946 .{ }^{24}$ Quieren estar más cerca de España para seguir la evolución política

\footnotetext{
${ }^{18}$ Será la segunda y última vez que se reúnen las Cortes Republicanas. Asisten representaciones de Francia, URRS, Suecia, Checoslovaquia, Colombia, Ecuador, Nicaragua, Perú, Uruguay y Venezuela. No acuden Estados Unidos ni Gran Bretaña.

${ }^{19}$ Llegaría a ser Vicepresidente $1^{\circ}$ de la Cámara. Cuando Jiménez de Asúa acceda a la Presidencia de la República en 1962 tras la muerte de Martínez Barrio.

${ }^{20}$ El día $1^{\circ}$ de agosto de 1945 , Negrín que ha viajado a Méjico, solicita públicamente en un acto celebrado en el Palacio de Bellas Artes de Méjico el restablecimiento de la Presidencia de la República, si se quiere que presente la dimisión de su gobierno.

${ }^{21}$ La sesión había comenzado a las tres de la tarde y la promesa de Martínez Barrio fue a las cuatro y veinte. A partir de 1962 y para evitar que la presidencia de las Cortes recayera en Dolores Ibarruri que era Vicepresidenta, se acuerda que a partir de este momento se fusionen las dos Presidencias — República y Cortes Republicanas — en el titular de la Presidencia de la República.

${ }^{22}$ Martínez Barrio, Jiménez de Asúa y José Maldonado.

${ }^{23}$ De agosto e 1945 a junio de 1977 ocupan la Presidencia del Gobierno Giral (IR), Llopis (PSOE), Álvaro de Albornoz (IR)2 veces, Gordon Ordax (PSOE) 2 veces, Emilio Herrera, Claudio Sánchez Albornoz y Fernando Valera. Hay un cuadro muy completo con los nombres de todos los Presidentes y los Ministros, duración en el cargo, adscripción partidista etc., en Cabeza, Sonsoles. Op. Cit. Págs. 12 y 13

${ }^{24}$ El gobierno francés le ofrece una residencia oficial en la Avenida Poincaré, al lado de la ofrecida al gobierno republicano. Ya están en Francia todas las instituciones republicanas en el exilio. Jefatura del Estado, que asume también la de las Cortes, y la Presidencia del Gobierno. A poco de instalarse en París fallece en esta ciudad el líder socialista Largo Caballero el día 22 de marzo de 1946.
} 
de su país tras la segunda guerra mundial y las decisiones que habían de tomar los vencedores del Eje. Se da la curiosa circunstancia que Francia, que había reconocido el gobierno de Franco en abril del 39 , acepta la presencia del gobierno republicano en su territorio, le facilita un edificio como sede del mismo y otorga carta diplomática al Presidente y los ministros. ${ }^{25}$ Los republicanos del exilio viven un periodo de euforia y esperanza en la recuperación de la República que va a durar hasta el año 1950. Del Valle califica esta etapa como «la euforia de la esperanza». ${ }^{26}$

El traslado a Francia y en el clima de legalidad en el que se mueven se plantea una doble tesitura de índole jurídica constitucional. Por una parte los defensores del mantenimiento de las Instituciones republicanas en el exilio, argumentando que para ello no hacía falta territorio propio, bastando la ficción jurídica, reconocida internacionalmente, de la extraterritorialidad. De otra, los que afirmaban que no podía haber instituciones sin un territorio donde asentarse. Triunfó la primera tesis y dio comienzo la etapa francesa de las instituciones republicanas, dentro del ciclo de la llamada España peregrina. ${ }^{27}$

\section{EL CISMA DEL EXILIO}

Los republicanos españoles, obligados al exilio tras la victoria franquista, no solo tuvieron en contra la persecución de la GESTAPO, sino también la de la propia policía franquista, amén del no reconocimiento de la potencias occidentales en base al principio de «no intervención». Por si no les bastase con ello, surge dentro de la clase política republicana una rivalidad llevada a sus últimas consecuencias entre los partidarios de Juan Negrín ${ }^{28}$, último Jefe del Gobierno designado por D. Manuel Azaña y los de Prieto ${ }^{29}$. Además de las posibles dife-

${ }^{25}$ El Gobierno republicano se instala en un local en la 35 Avenue Foch de Paris.

${ }^{26}$ Op. Cit. Pág. 191

${ }^{27}$ En este sentido se celebran Congresos por parte de las distintas fuerzas políticas en territorio francés. Es el caso de Izquierda República, que se reúnen en Montauban, o la UGT en Toulouse. Esta ciudad fue la capital de la emigración republicana en Francia tras la liberación y consiguiente expulsión de los alemanes

${ }^{28}$ Acaba de publicarse una obra que recoge los «Textos y Discursos Políticos» de Negrín por el Centro de Estudios Políticos y Constitucionales con una extensa introducción de Enrique Moradiellos. Madrid, diciembre 2010. Es una obra fundamental para seguir la trayectoria política desde el primer artículo publicado en El Socialista el 28 de mayo de 1929, con el que se integra en el PSOE, hasta la carta dirigida el 6 de septiembre de 1952 a Herbert Matthews, periodista del New York Times, al que había conocido como corresponsal de guerra en España.

${ }^{29}$ La correspondencia entre Prieto y Fernando de los Ríos, con un estudio introductorio de 
rencias de carácter táctico, de modo especial la colaboración con los comunistas, hay otro motivo de enfrentamiento. Era el control y administración de los medios económicos de los que podía disponer la República en el exilio, destinados a prestar ayuda a los numerosos republicanos que habían abandonado España tras la derrota de 1939.

Negrín se había hecho cargo de la SERE (Servicio de Emigración de los Republicanos Españoles), creada en 1937 para atender las necesidades de los primeros refugiados que llegan a Francia. Más tarde y ya en Londres y con sus fondos creó el Instituto Español y la Fundación Luis Vives para facilitar el incremento de las relaciones culturales entre Gran Bretaña y el exilio español ${ }^{30}$. Hay que tener en cuenta que una parte muy selecta de los republicanos del exilio se habían instalado en la capital británica y participaban en las universidades de aquel país. Por otra parte Londres, desde el inicio de la guerra mundial, se había convertido en lugar de refugio seguro para muchos gobiernos expulsados de sus respectivos países tras la invasión alemana. ${ }^{31}$

Junto a la SERE surge la JARE (Junta de Auxilio a los Refugiados Españoles), creada por la Diputación Permanente el 28 de julio de 1939, nombrándose Presidente de la misma a D. Luis Nicolau D’Olwer. Desde el principio fue controlada por Prieto, quien maneja los fondos derivados del tesoro del famoso yate Vita ${ }^{32}$. Negrín valora la carga en joyas del barco en más de cuarenta millones de dólares ${ }^{33} y$ pide explicaciones a Prieto sobre el mismo. ${ }^{34} \mathrm{~A}$ su vez éste exige a Negrín que rinda cuentas de la administración que ha hecho de los bienes republicanos que controla desde su salida de España. ${ }^{35}$ Como señala Sonsoles Cabeza el Gobierno Negrín, aunque muy discutido en cuanto a su legitimidad por sus propios compañeros socialistas, se mantiene hasta 1945, cuando, al ser ocu-

\footnotetext{
Octavio Ruiz-Manjón, ha sido publicada por el Centro de Estudios Políticos y Constitucionales en diciembre de 2010, bajo el título «Indalecio Prieto- Fernando de los Ríos: Epistolario 1924-1948»

${ }^{30}$ Véase Del Valle. Op. Cit. Pág. 51.

${ }^{31}$ Según propia confesión de Negrín disponía de alrededor de doscientos cincuenta millones de francos en 1939. Véase Del Valle. Op. Cit. Pág. 33.

32 Era un lujoso barco de recreo a nombre de un ciudadano filipino llamado Marino Gamboa. En el mismo se trasladó desde Francia a Méjico un tesoro en joyas, sacadas de las cajas fuertes de los bancos españoles y guardadas en mas de cien maletas. Tras muchas vicisitudes, este cargamento pudo llegar a Méjico y allí fue administrado por la Diputación Permanente de las Cortes, bajo el control directo de Prieto.

${ }^{33}$ Véase Del Valle. Op. Cit. Pág. 36.

${ }^{34}$ La JARE se crea en París el 28 de julio de 1939 por parte de la Diputación Permanente. La preside el ex embajador de la República en Londres D. Pablo de Azcárate.

${ }^{35}$ Estas diferencias vienen reconocidas en la obra de Prieto, «Convulsiones de España» II y III.
} 
pado el cargo de Presidente de la República por Martínez Barrio, no le queda otra alternativa que presentar la dimisión. Negrín no atiende la reclamación de los distintos gobiernos republicanos en el exilio iniciada por Giral, aludiendo a la dificultad de aportar las pruebas sobre estos fondos por la dispersión de documentos provocada por la salida precipitada de España. ${ }^{36}$

Ambas asociaciones asumieron el alquiler de los barcos necesarios para trasladar millares de refugiados desde Francia a Hispanoamérica, en una operación que duró tres años y que contó con la necesaria e inestimable colaboración del consulado de Méjico ante Vichy. Prieto entró en contacto con el embajador franquista José Félix de Lequerica para una posible devolución del tesoro del Vita a España a cambio de permitir el regreso de los refugiados. Pero las conversaciones no prosperaron. ${ }^{37}$

A la vista de la situación y para darle la máxima legalidad, el gobierno mejicano decide asumir el control, custodia y administración de los bienes de la JARE que pasaban a formar parte de la CAFARE (Comisión Administradora de los Fondos de Auxilio a los Republicanos españoles) ${ }^{38}$. El 6 de agosto de 1945 el Gobierno de Méjico disuelve la CAFARE y entrega al Gobierno Giral la liquidación de la misma y el estado de las existencias de que disponía. ${ }^{39}$

La situación financiera de la República en el exilio era desesperada. Algunos países europeos atienden la petición de auxilio y ayudan económicamente. ${ }^{40}$ Durante el Gobierno Albornoz se emiten los llamados «Bonos de Liberación» para allegar fondos. Lamentablemente tuvieron muy escasa acogida. La mayor parte de los escasos recursos que con el paso del tiempo llegaron a contar los gobiernos republicanos, se destinaban a nutrir el presupuesto del Ministerio de Emigración para atender las necesidades de los refugiados españoles. ${ }^{41}$

\footnotetext{
${ }^{36}$ Destaca la enérgica reclamación presentada por Fernando Valera, ministro de Hacienda del Gobierno Llopis, ante Negrín, pidiéndole cuentas sobre los bienes de la República que ha administrado y exigiendo su inmediata devolución. Véase Cabeza, Sonsoles: Op. Cit. Págs. 136-8

${ }^{37}$ Según Del Valle, estas tuvieron lugar en el domicilio parisino el Doctor Teófilo Hernando. Actuó de testigo por parte de Lequerica el entonces agregado militar a la embajada de España en París Antonio Barroso, quien más tarde ocuparía el Ministerio del Ejército. Hubo la mejor disposición por ambas partes para este intercambio, que lamentablemente fue rechazado por Franco. Véase Op. Cit. Pág. 42.

${ }^{38}$ Fue creada por Decreto de la Presidencia de Méjico de 27 de noviembre de 1943 y publicado en la prensa mejicana el 1 de diciembre de dicho año. En el fondo se trataba de «una incautación de los bienes de la JARE por el Gobierno mejicano (lo) que causó muy mala impresión entre los refugiados españoles» Véase Del Valle: Op. Cit. Pág. 71.

${ }^{39}$ Ibidem. Pág. 121.

${ }^{40}$ Es el caso de Francia, Gran Bretaña, Suiza y los países nórdicos.

${ }^{41}$ El Ministerio fue creado por el Gobierno Giral, por Decreto de 26 de noviembre de 1945. Su primer titular fue Trifón Gómez, sindicalista de la UGT.
} 


\section{LA COYUNTURA INTERNACIONAL}

El final de la guerra civil española y el inicio del forzado y siempre trágico exilio republicano se solapan prácticamente en el tiempo con el inicio de la segunda guerra mundial. En principio en ella medirán sus fuerzas, de un lado, Gran Bretaña y Francia como defensoras del orden parlamentario y democrático y de otro Alemania e Italia, ejemplos de totalitarismo racista o fascista. Pero se da el caso curioso que ambas potencias han sido las aliadas de los sublevados contra la República, mientras que, en teoría, Francia e Inglaterra han mantenido el principio de No Intervención en los asuntos internos de España. La República Española no encontrará más aliado que la Unión Soviética, quien poco más tarde se incorporará a la lucha contra las potencias del Eje. De este modo, nos encontramos con la paradoja muy significativa de que los vencedores de la guerra serán los adversarios del fascismo- salvo el caso de la Unión Soviética, régimen tan totalitario como los del Eje, al principio aliado de Alemania hasta que el nazismo comete la imprudencia de romper el pacto de no agresión que habían firmado. A sensu contrario los vencidos serán los aliados de Franco en la guerra civil española. La lógica política permitía sospechar que tras la derrota italoalemana, las potencias occidentales negarían el pan y la sal al régimen franquista, vencedor de la República, en parte por la ayuda de Alemania e Italia. Así lo entendieron desde el primer momento los republicanos españoles. En este sentido hay que entender la famosa proclama del Presidente Negrín: «Resistir es vencer», en la creencia de que el estallido de la guerra mundial, por entonces solo europea, permitiría a las potencias occidentales ayudar a la República y eliminar al aliado de Hitler y Mussolini. Pero la guerra española termina el uno de abril del 39 y hasta el mes de septiembre no tiene lugar el inicio de la conflagración europea.

Terminada la guerra tiene lugar un replanteamiento político e ideológico con condena expresa de los regímenes totalitarios, aunque entre los postulantes de este programa, se encontrara paradójicamente la Unión Soviética. Se abría, pues, un portillo para la recuperación de las instituciones republicanas que estaban desperdigadas por el mundo a consecuencia del exilio. De hecho, la mayor parte de los estudiosos de este periodo de la historia española hablan de esta posible recuperación, a tenor del nuevo esquema de la política internacional que se diseña tras Yalta, en febrero del 45, y Potsdam en agosto del mismo año. ${ }^{42}$

${ }^{42}$ Sonsoles Cabeza titula «La esperanza republicana. 1939-1951» la primera parte de su libro. José María del Valle define el Gabinete Giral de 1945 como «el gobierno de la esperanza». En realidad estas expectativas respondían a la lógica más elemental, pero sin embargo pronto se vieron defraudadas.

(C) UNED. Revista de Derecho Político 
Los republicanos españoles toman conciencia de asistir a una posible recuperación de la República si lograban la condena del franquismo, condición sine qua non para su vuelta a España. Saben que los tres grandes- USA, URSS y UK- han acordado prohibir la entrada de nuestra Patria en la futura organización internacional que se está gestando en San Francisco, mientras se mantenga el régimen franquista. ${ }^{43}$

En el ínterin de la guerra mundial, un grupo de exiliados españoles reunidos en La Habana a instancias del Doctor Gustavo Pittaluga el 22 de octubre de 1943, a la vista de los acontecimientos, han decidido la creación de la llamada «Junta Española de Liberación», con el objetivo de promover la unidad de las distintas facciones republicanas, y presionar sobre los gobiernos libres que luchan contra el fascismo italo alemán para lograr la restauración de la República en España. Nombran Presidente de la Junta a Martínez Barrio y Secretario de la misma a Indalecio Prieto. ${ }^{44}$

Su labor será muy importante en el ámbito del reconocimiento internacional de la República en el exilio. Suyo es el Memorándum que dirigen a los miembros de la Conferencia de San Francisco reunidos el 25 de abril de 1945 en el Teatro de la Ópera, para preparar la Carta de las futuras naciones Unidas, es decir la ONU. En ella plantean oficialmente lo que en el ámbito diplomático internacional se conocería a partir de ahora como «el caso español». ${ }^{45}$ La Junta ha elaborado un Memorándum sobre la situación española que presenta a los delegados en San Francisco ${ }^{46}$. El embajador mejicano Quintanilla defiende la propuesta de exclusión de España de la futura Organización Internacional, propuesta que fue aprobada por aclamación ${ }^{47}$. A partir de este momento, la Junta Española de Liberación suspende sus actividades para no interferir en la acción diplomática que en el mismo sentido lleva a cabo el Gobierno Giral ${ }^{48}$. En 1946 el gobierno Giral es reconocido por Guatemala, Panamá y Venezuela, que asumen la condena de la

${ }^{43}$ Pero el 24 de mayo de 1944, cuando aún no ha terminado la guerra, Churchill pronuncia un discurso en los Comunes alabando a Franco. Para algunos republicanos, conocedores del mismo, fue un jarro de agua fría que anticipaba lo que habría de venir después.

${ }^{44}$ Véase Del Valle. Op. Cit. Pág. 77

45 Además de la acción de la Junta, Prieto y Negrín, cada uno por su cuenta dada la mala relación existente entre ambos, se mueven cerca de los gobiernos occidentales buscando la condena internacional del régimen franquista.

${ }^{46}$ Un extracto amplísimo del texto del Memorándum en Del Valle, Op. Cit. Págs. 91 y ss.

${ }^{47}$ El tema ha generado una amplia bibliografía. Véase por todos Portero, Florentino: «Franco aislado. La cuestión española. 1945-1950». Madrid, 1989.

${ }^{48}$ Es el primer gobierno encargado por el Presidente Martínez Barrio tras la dimisión de Negrín. Están representados todos los grupos republicanos del exilio salvo los comunistas, un sector de los socialistas y Esquerra Republicana, cuyo máximo dirigente, Tarradellas, también se niega a participar en el mismo. 
ONU del 12 de diciembre de $1946 .{ }^{49}$ En el mismo año se suman Polonia, Yugoslavia, Checoslovaquia, Rusia, Rumania y Bulgaria. Solo desacatan el aislamiento internacional de retirada de embajadores y exclusión de todos los organismos internacionales, recomendado por la ONU, Portugal y Argentina. ${ }^{50}$

Simultáneamente a la aparición de la Junta Española de Liberación en La Habana, surge en España a finales de 1943, la llamada «Alianza Nacional de Fuerzas Democráticas ${ }^{51}$ que cuenta con personajes del interior, conectados con los monárquicos juanistas, como el General Aranda, y sectores de obediencia democristiana ${ }^{52}$. La Alianza está dirigida desde la cárcel por Regulo Martínez Sanz. Pretendía aglutinar a todas las fuerzas de la oposición antifranquista en el interior. ${ }^{53}$

El gobierno republicano, fiel a su deseo de mantener la máxima legalidad en todas sus actuaciones, recupera el 26 de marzo de 1946, la Junta Permanente de Estado, institución creada en 1933 para asesorar al Gobierno. ${ }^{54}$ El líder socialdemócrata Indalecio Prieto inicia su aproximación a los monárquicos manteniendo en Londres conversaciones con José Maria Gil Robles, el ex líder de la CEDA, bajo el patrocinio de Bevin, que terminarían en la firma del llamado Pacto de San Juan de Luz el 8 de octubre de 1948. La iniciativa de Prieto contó desde el principio con la enemiga de destacados personajes republicanos como Álvaro de Albornoz y todo el sector negrinista ${ }^{55}$. La desconfianza

${ }^{49}$ Es la famosa Resolución 39 aprobada en Lake Succes que recomienda la retirada de embajadores. Frente a lo que suele afirmarse no suponía la ruptura de relaciones diplomáticas, sino bajar el nivel de las mismas. La mayoría de las potencias occidentales mantuvieron la representación, por evidentes razones de índole económica, pero a nivel de encargados de negocios.

${ }^{50}$ De hecho el delegado argentino en la ONU, el Dr. Arce, fue el más entusiasta defensor del derecho de España a pertenecer a la nueva organización y en evitar su condena internacional.

${ }^{51}$ Publican un Manifiesto recogido por primera vez por José María del Valle. Op. Cit. Págs. 136 y ss.

${ }^{52}$ Del Valle afirma que colaboró también el financiero Don Juan March Ordinas. Op. Cit. Pág. 140. Según Del Valle fueron traicionados por un infiltrado de la policía llamado Luis Alfaro.

${ }^{53}$ Del 16 al 18 de junio de 1960 tiene lugar en París una reunión de la que surge ARDE (acción Republicana Democrática Española) para aglutinar a todos los partidos republicanos en el exilio, en una acción idéntica a la postulada para el interior por la Alianza de Fuerzas Democráticas.

${ }^{54}$ Forman parte de la misma el Presidente de la República (Martínez Barrio) y los ex Presidentes (Alcalá Zamora), el Presidente del Gobierno (José Giral) y los ex Presidentes (Lerroux, Chapaprieta) y los Presidentes de Cataluña y Euzkadi.

${ }^{55}$ Prieto apuesta por una alianza de monárquicos y socialistas para hacer más factible el derrocamiento de Franco. El líder socialista es consciente de que un sector de los que apoyaron a Franco para levantarse contra la República esperaban el restablecimiento de la Monarquía. Al afianzarse el poder personal del Caudillo se lo reprochan y le piden una institucionalización del Régimen. Franco sabe que las cabezas más visibles del ejército y de más alta graduación, entre ellos Kindelán, 
sobre el buen resultado de esta acción de posible alianza con los monárquicos se ve refrendada por la entrevista Franco -Don Juan a bordo del yate Azor en agosto de $1948 .^{56}$ La reunión del Azor fue un golpe de muerte para las pretensiones de Prieto, quien había conseguido el respaldo de los socialistas en un Congreso celebrado recientemente en Toulouse, la auténtica capital del exilio republicano. ${ }^{57}$

Entretanto Franco prosigue la institucionalización de su régimen iniciada con el Fuero del Trabajo promulgado en plena guerra civil ${ }^{58}$. A esta, primera de las futuras Leyes Fundamentales, seguiría la de Cortes $^{59}$, la de Referéndum Nacional ${ }^{60}$ y la Ley de Sucesión a la Jefatura del Estado ${ }^{61}$. Esta última declara España constituida en Reino y faculta al Jefe del Estado, es decir Franco, para designar sucesor a título de Rey o de Regente, así como la posibilidad de revocar el nombramiento. La norma cerraba el paso de una restauración pacífica de la República, pero también de la Monarquía, ya que lo que establecía era una instauración monárquica, una especie de monarquía electiva, como el modelo visigótico, en la que, además, la Iglesia Católica tendría una importancia decisiva, ya que el sucesor habría obligatoriamente de ser católico.

Pero la baza decisiva para la permanencia del franquismo fue el levantamiento de sanciones contra España por parte de la ONU el día 4 de noviembre de 1950 que dejaba sin efecto la Resolución 39 de 12 de diciembre de 1946. Suponía el reconocimiento del régimen y dejaba la puerta abierta para la incorporación de la España de Franco al resto de organizaciones internacionales, amén de darles un salvocon-

Orgaz, Saliquet, Varela, Ponte, Solchaga y Monasterio, están por Don Juan de Borbón. Éste a su vez, y por primera vez, empieza a distanciarse de Franco con el Manifiesto de Lausanne el 19 de marzo de 1945. Se habla incluso de un intento de pronunciamiento militar desde la Capitanía General de Barcelona donde el General Solchaga lo proclamaría Rey. Pero el Conde de Barcelona se opone. Véase Del Valle. Op. Cit. Pág. 144

${ }^{56}$ A la misma asisten, aparte de Don Juan, su hermano Don Jaime, el duque de Sotomayor y Julio Danvila por parte del Conde de Barcelona que ha llegado a San Sebastián a bordo del Saltillo, un pequeño yate del armador vasco Pedro Galíndez. Franco le recibe en el Azor acompañado de D. Pablo Martín Alonso, Jefe de la Casa Militar y futuro Ministro del Ejército. En esta reunión se acuerda la venida a España del Príncipe Don Juan Carlos y el programa de estudios que ha de seguir.

${ }^{57}$ Los intentos de alianza entre los republicanos del exilio y los monárquicos del interior tenían como objetivo primordial la salida de Franco. Pero el problema político de fondo era el tipo de régimen a implantar en España una vez desaparecido el franquismo. Se apostaba por un referéndum previo sobre la forma de gobierno que despejara la opción entre republica y monarquía.

${ }^{58}$ El 9 de marzo de 1938.

${ }^{59}$ El 17 de julio de 1942, modificada por Ley de 9 de marzo de 1946.

${ }^{60}$ De 22 de octubre de 1945

${ }^{61}$ De 27 de julio de 1947. 
ducto a los países occidentales para el restablecimiento total de relaciones diplomáticas. A partir de aquí se desbroza el camino en detrimento de las pretensiones republicanas. España ingresa en la UNESCO ${ }^{62}$, la Santa Sede acuerda el Concordato ${ }^{63}$ y los Estados Unidos firman un Convenio, no un Tratado como decía la prensa española ${ }^{64}$. El camino para la integración de España en la ONU como miembro de pleno derecho estaba expedito. El ingreso, auténtico espaldarazo a nivel internacional, tiene lugar el 14 de diciembre de $1955 .{ }^{65}$ Una vez más se daban las contradicciones tan frecuentes en las relaciones internacionales. Franco recibía al mismo tiempo condenas verbales y ayudas económicas junto a reconocimientos internacionales. La República Española, en cambio, recibe entusiastas adhesiones morales, mientras poco a poco se ve abandonada por sus antiguos aliados.

Los republicanos, entretanto crean la «Orden de la Liberación de España», para premiar a personas y países que hayan defendido la causa de la República. ${ }^{66}$

Los próximos años sesenta serán muy difíciles para la República en el exilio. El régimen franquista se va afianzando y ganando en la consideración internacional. España se incorpora poco a poco a las grandes organizaciones supranacionales. Queda excluida de la NATO y también del Mercado Común Europeo, aunque logra un tratado preferencial con los países europeos que la aceptan económicamente pero la rechazan políticamente. España es Europa y así lo atestigua la geografía, pero el mapa político y el geográfico no van al unísono. Políticamente España sigue siendo diferente de las restantes democracias europeas. Como señala Huntington a principios de los setenta solo quedan en la Europa occidental tres dictaduras: España, Portugal y Grecia; y de todas ellas será la española la última en desaparecer.

\section{DE AZAÑA A MALDONADO}

Con la dimisión de D. Manuel Azaña el 27 de febrero de 1939 puede decirse que empieza el exilio de la II República Española. Es cierto que hasta el $1^{\circ}$ de abril no se da por oficialmente terminada la contienda, pero el mes de marzo va

\footnotetext{
${ }^{62}$ El 17 de noviembre de 1952.

${ }^{63}$ El 28 de agosto de 1953.

${ }^{64}$ El 26 de septiembre de 1953.

${ }^{65} \mathrm{El}$ ingreso es fruto de un pacto entre USA y URSS. Entran 16 países entre ellos el bloque centroeuropeo sometido a la influencia soviética y por parte occidental Italia, Portugal, Irlanda y España. España tuvo 55 votos a favor en la Asamblea General y dos abstenciones (Bélgica y Méjico). La oposición belga se explica por la negativa del gobierno española a entregar a León Degrelle.

${ }^{66}$ Decreto de 3 de septiembre de 1947. Se considera sucesora de la «Orden de la República», creada por Decreto de 21 de julio de 1932.
} 
a ser el tiempo de la desbandada desorganizada. Todos, políticos y ciudadanos, intentan salir por la frontera francesa o el puerto de Alicante. Las playas francesas o argelinas serán el destino de miles y miles de españoles. Hoy cuesta trabajo imaginar la moral que los dirigentes republicanos supieron mantener en el exilio en tan difíciles como dramáticas jornadas. Se abre un periodo que va a durar cerca de cuarenta años en los que los gobernantes republicanos intentarán por todos los medios mantener la legalidad y la legitimidad de las instituciones republicanas en el exilio. En este periodo suceden a D. Manuel Azaña tres Presidentes de la República y siete Jefes de Gobierno, cuya trayectoria es conveniente analizar, aunque sea muy brevemente.

Azaña dimite ante el Presidente de las Cortes, de acuerdo con lo establecido en la Constitución republicana, pero el Gobierno Negrín se mantiene hasta el final de la guerra y después permanece como el legítimo representante del Ejecutivo hasta 1945, tras la elección como Presidente Provisional de D. Diego Martínez Barrio. He señalado ya la exigencia formal reclamada por Negrín para presentar la dimisión de su gobierno a la elección de un nuevo Presidente de la República como sucesor de Azaña. Dicha elección se regula por la Constitución de 1931 y la Ley de Elecciones del Presidente de la República de 3 de julio de $1932 .{ }^{67}$

Durante estos seis años el Dr. Negrín defiende su legitimidad, administra los bienes de la SERE, mantiene contactos con los gobiernos que luchan contra el Eje, mantiene sus diferencias con Prieto surgidas durante la guerra y recorre medio mundo pidiendo la caída de Franco y el reconocimiento de la República como el legal y legitimo régimen político de los españoles. Había accedido a la Presidencia del Consejo de Ministros por primera vez el 18 de mayo de 1937 hasta el 4 de abril de 1938 que preside su segundo Gobierno llamado de Unión Nacional, un ejecutivo que se mantiene hasta el final de la guerra en territorio nacional y posteriormente hasta 1945 ya en el exilio. ${ }^{68}$ Su gestión ha sido objeto de los más encontrados comentarios. Hombre de gran talla intelectual, cargó sobre sus hombros la responsabilidad de dirigir el gobierno republicano en plena guerra y en circunstancias internacionales verdaderamente hostiles, con evidente violación de la carta de Ginebra por parte de las democracias europeas. A su salida de España residió en Londres y posteriormente fija su residencia en París

\footnotetext{
${ }^{67}$ Consta de 19 artículos. El texto en Sevilla Andrés: «Constituciones y otras Leyes y Proyectos Políticos de España». Madrid, 1969. Vol. II. Págs. 251 y ss.

${ }^{68}$ Véase Arraras, Joaquín: «Historia de la Segunda República Española». Madrid, Ed. Nacional, 1968. Vol. IV. Pág. 432.
} 
donde muere el 14 de noviembre de 1956. ${ }^{69}$ Negrín fue el último Presidente del Gobierno designado por Azaña y el primero del exilio republicano.

Elegido Presidente de la República D. Diego Martínez Barrio encarga el Gobierno a D. José Giral quien se mantiene al frente del mismo de agosto de 1945 a febrero de 1947. Dio entrada en el gobierno a Santiago Carrillo como Ministro sin cartera en representación del PCE. ${ }^{70}$ Giral convoca Cortes para obtener la confianza del parlamento en la más ortodoxa línea del régimen parlamentario. Estas se celebran en Méjico los días 7, 8 y 9 de noviembre de 1945, reuniéndose las Cortes Republicanas por tercera y última vez en la «sala del Cabildo» del Palacio del Gobierno en México D.F., con la asistencia de 142 diputados $^{71}$. José María del Valle califica este gabinete como el «Gobierno de la Esperanza» ${ }^{72}$. Don José Giral, ilustre catedrático de la Universidad Central de Madrid, de la que llegó a ser Rector, había ocupado la presidencia del Gobierno español por encargo de Azaña del 19 de julio al 5 de septiembre de 1936, en un gabinete integrado exclusivamente por republicanos. Sucedía a Martínez Barrio ${ }^{73}$ y fue sucedido en la Presidencia por el Gabinete Largo Caballero ${ }^{74}$.

Presentada la dimisión por Giral, el Presidente Martínez Barrio encarga el Gobierno al socialista Rodolfo Llopis. Era el Secretario General del PSOE, quien

${ }^{69}$ A su muerte los herederos hacen entrega a las autoridades españolas en la Embajada en París de la documentación relativa a la entrega del oro depositado en el Banco de España a los rusos como pago de los suministros soviéticos a la República, ante la negativa franco británica basada en la teoría de la No Intervención. Desde varios sectores del exilio fue muy criticada esta entrega a las autoridades franquistas. Durante mucho tiempo fue acusado de estar vendido a Rusia. Los trabajos del Profesor Viñas han dejado claro que el depósito entregado a la URSS era el pago obligado a las entregas de material de guerra recibidas por el ejército republicano. Hoy contamos con análisis biográficos del político canario, entre otros, del profesor Miralles («Juan Negrín. La República en guerra» Madrid, 2003) y Enrique Moradiellos («Don Juan Negrín». Barcelona, 2006). Este último ha editado recientemente los «Textos y Discursos políticos». Madrid, 2010.

${ }^{70}$ También fueron Ministros sin cartera de este gobierno D. Ángel Osssorio y Gallardo, como Independiente, D. Luis Nicolau D’Olwer de Acció Republicana Catalana, Alfonso Rodríguez Castelao de la ORGA y Rafael Sánchez Guerra como Republicano Moderado. El nombre de este último no se hizo público porque se encontraba aún en España el interesado y había que adoptar precauciones.

${ }^{71}$ Véase Cabeza, Sonsoles: Op. Cit. Pág. 47.

${ }^{72}$ Véase Op. Cit. Págs. 113-229

${ }^{73}$ Su gobierno solo duró un día: el 19 de julio de 1936.

${ }^{74}$ Fue dos veces Presidente del Ejecutivo. Su primer Gobierno se mantuvo del 5 de septiembre al 5 de noviembre, integrado por socialistas, comunistas y nacionalistas vascos. El segundo del 5 de noviembre de 1936 a 18 de mayo de 1937, con participación de la CNT. Bajo este Gobierno tuvo lugar el traslado a Valencia del Ejecutivo y la Presidencia de la República, día 7 de noviembre de 1938, dejando en Madrid una Junta de Defensa. 
asume la tesis prietista de acercamiento a las fuerzas del interior que luchan por derribar el régimen franquista y mantener la política preconizada por Naciones Unidas para el aislamiento internacional de Franco. Era el corolario lógico a la actitud defendida por Prieto de la colaboración con los monárquicos que se plasmaría en el llamado Pacto de San Juan de Luz, bendecido por el gobierno británico. Naturalmente al actuar como la voz de los prietistas, se había de entrada ganado la animadversión de los negrinistas, enemigos de la negociación con los partidarios de Don Juan. El Gobierno Llopis toma posesión en febrero de 1947 y termina en agosto del mismo año. Apenas dura poco más de un semestre. Durante este periodo tiene lugar la promulgación de la Ley de Sucesión a la Jefatura del Estado, calificada por los republicanos como «simulación democrática del franquismo», y el consiguiente Manifiesto de Don Juan de Borbón en contra de la misma. ${ }^{75}$ La España franquista queda excluida de la Conferencia de Estados Europeos y el Plan Marshall y el Gobierno Llopis persiste en su tarea cerca de la ONU para lograr el asilamiento internacional de España. Llopis entrega la cartera de Economía en su gobierno al comunista Uribe lo que provoca las iras de Prieto y en última instancia la crisis de gobierno.

El tercer gobierno republicano en el exilio lo preside Álvaro de Albornoz. Dura de agosto de 1947 al mes de agosto de 1949. Durante el mismo se sigue muy de cerca la reanudación del llamado «problema español» por parte de la ONU en la reunión de Lake Succes. Para premiar la labor de los diplomáticos que se habían manifestado a favor de la República con su condena del régimen de Franco, Albornoz crea la «Orden de la Liberación de España» para premiar los servicios prestados. ${ }^{76}$ La actitud vacilante de antiguos aliados y el fracaso de las conversaciones con los monárquicos evidenciadas en la reunión Franco-Don Juan en el Azor, le llevan a presentar la dimisión de su gobierno. Martínez Barrio tras las consultas de rigor a los líderes políticos, le vuelve a dar el encargo y Álvaro de Albornoz pone en marcha su segundo gobierno manteniendo este gabinete desde febrero de 1949 al mes de agosto de 1951 en que presenta su dimisión.

${ }^{75}$ Prieto y un sector importante del PSOE son conocedores de la actitud del ejército español que se manifiesta mayoritariamente a favor de la restauración monárquica. De ahí su deseo de un pacto con los partidarios de Don Juan para derribar el franquismo y más tarde plantear un referéndum sobre la forma de gobierno, cuyo resultado, fuera el que fuese, debía ser respetado por todos.

${ }^{76}$ Decreto de 3 de septiembre de 1947. Con ella fueron condecorados Luis Companys (a título póstumo) y Pablo Casals entre los españoles. Entre los extranjeros Mauriac, Bataillon, Sartre, Sarrailh, Maria Casares, Albert Camus, Tito, Lázaro Cárdenas, Ávila Camacho y Rómulo Betancourt entre otros. 
El Presidente Martínez Barrio encarga la formación del nuevo gobierno a Félix Gordón Ordax quien, al igual que su antecesor Álvaro de Albornoz, ocupó la jefatura del Gobierno en dos ocasiones. La primera de agosto de 1951 a enero de 1956. Cuando la ONU levanta las sanciones a la España de Franco y le acepta en su seno, Gordón presenta la dimisión, no aceptada por el Presidente que le vuelve a dar su confianza, manteniéndose en este segundo gobierno hasta el 17 de abril de 1960. Llevo a cabo una intensa labor diplomática visitando Yugoslavia, especialmente invitado por el Presidente Tito, amén de casi todas las repúblicas hispanoamericanas $^{77}$. Por motivos de salud, más el quebranto producido durante su mandato por los fallecimientos de Negrín y José Antonio Aguirre Lekube ${ }^{78}$, además de la nueva situación internacional, presenta su dimisión de forma irrevocable.

El Presidente encarga en mayo de 1960 al General Emilio Herrera la formación de un nuevo gobierno que sería el séptimo del exilio, manteniéndose hasta el mes de febrero de 1962. Durante su mandato se vieron obligados a abandonar el edificio de la avenida Foch ocupadas desde hacia 16 años por el gobierno republicano en el exilio, alquilando un nuevo local en el 56 del Boulevard Jean Jaures, en las afueras de París, mucho más pequeño y modesto, lo que obligó a reducir el número de funcionarios e incluso los departamentos ministeriales. ${ }^{79}$ Durante su mandato se creó la «Orden de la Lealtad a la República Española» y se constituyó en París la Acción Republicana Democrática Española ${ }^{80}$, con el objeto de unificar en una sola organización todas las fuerzas republicanas en el exilio. En política exterior el General Herrera firmó un acuerdo de colaboración con el general portugués Humberto Delgado el día 10 de febrero de 1961, a fin de conseguir la liberación de ambos países sometidos a las dictaduras de Franco y Salazar. ${ }^{81}$ La muerte de Martínez Barrio en París, el uno de enero de 1962, dejaba vacante la Presidencia de la República a la que accede el Vicepresidente primero de las Cortes, profesor Jiménez de Asúa, ante el que el General Herrera presenta la dimisión ${ }^{82}$.

${ }^{77}$ Durante su mandato se constituye el Consejo Federal Español del Movimiento Europeo que preside Salvador de Madariaga.

${ }^{78}$ Tuvo lugar el 22 de marzo de 1960. Su cadáver fue trasladado a San Juan de Luz, siendo enterrado al lado de su madre. Véase Del Valle: Op. Cit. Pág. 336.

${ }^{79}$ Según Sonsoles Cabeza fue consecuencia de la actitud de la propietaria del inmueble que mantenía un conflicto con los inquilinos españoles, unido a las presiones de Franco para que los expulsaran de Francia. En este domicilio se mantuvo hasta su disolución en 1977. Véase Op. Cit. Pág. 297. Nota no 80.

${ }^{80}$ En París los días 16, 17 y 18 de junio de 1960 eligiéndose como presidente a José Maldonado. Véase Del Valle: Op. Cit. Págs. 340 y ss.

${ }^{81}$ El texto del llamado acuerdo luso español en Del Valle: Op. Cit. Págs. 338 y ss.

${ }^{82}$ El año 1962 va a ser especialmente trágico para la República Española en el exilio. El 11 de 
El ilustre penalista residía en Buenos Aires y allí el 28 de febrero de 1962, encargó a D. Claudio Sánchez Albornoz, la formación de un nuevo Gobierno ${ }^{83}$. El historiador constituye su gobierno el 8 de marzo manteniéndose al frente del ejecutivo republicano hasta el año 1971, lo que le hace el más largo de los gobiernos del exilio. Durante el mismo se sucedieron importantes acontecimientos relacionados con la vida política española. El día 14 de mayo de 1962 tiene lugar en Atenas la boda del Príncipe D. Juan Carlos con la Princesa Sofía, hija de los Reyes de Grecia ${ }^{84}$. Poco después los coloquios de Munich ${ }^{85}$ presididos por Maurice Faure y al que concurren 118 demócratas españoles la mayoría llegados del interior de España ${ }^{86}$. Fernando Valera como Ministro de Asuntos Exteriores de la República asiste en representación del Gobierno. En el Congreso se plantea el tema de la futura forma de gobierno de España, en el que discrepan republicanos y monárquicos. El día 15 de junio el Jefe del Gobierno, D. Claudio Sánchez Albornoz hace público un comunicado asumiendo las conclusiones adoptadas en Munich ${ }^{87}$. También se ponen de manifiesto las condiciones que habría de exigírsele a España si pretende formar parte de Europa. ${ }^{88}$

$\mathrm{Al}$ regreso los participantes fueron invitados a volver a Munich, so pena de pasar al destierro. Gil Robles optó por regresar a Europa. Otros fueron confinados mayoritariamente en las Islas Canarias. ${ }^{89}$

Todavía el Gobierno Sánchez Albornoz tendría que tener constancia de la decisión de Franco designando sucesor a título de Rey al Príncipe D. Juan Carlos, instaurando una monarquía de carácter electivo en su origen y saltándose las normas de la continuidad dinástica representadas por Don Juan de Borbón, como

febrero muere Indalecio Prieto y el 22 de diciembre D. José Giral. Poco a poco van desapareciendo las grandes figuras que protagonizaron e hicieron posible la II República.

${ }^{83}$ Ambos residían en la capital de Argentina porque en su Universidad ejercían su profesión de catedráticos. Allí permanecieron trabajando en sus cátedras mientras el Gobierno estaba en París.

${ }^{84}$ Este enlace fue aprovechado por los monárquicos para hacer patente sus reivindicaciones en pro de una restauración en la persona de Don Juan. La actitud del gobierno español ante la boda no paso de discreta.

${ }^{85}$ Celebrados e esta ciudad alemana los días 5 y 6 de junio de 1962,víspera del IV Congreso del Movimiento Europeo a celebrar los días 7 y 8 de junio.

${ }^{86}$ Según Del Valle 80 de España y 38 desde distintas ciudades de Europa y América. Véase Op. Cit. Pág. 348.

${ }^{87}$ El texto en Del Valle: Op. Cit. Pág. 351.

${ }^{88}$ Instituciones representativas, sufragio universal, libertades políticas y sindicales. En suma el modelo democrático del que estaba muy alejada la España de Franco.

${ }^{89}$ Las consecuencias de Munich se hicieron notar incluso en la órbita de Estoril. El Consejo Privado de Don Juan hace público un comunicado en el que se desliga de los acuerdos de Munich, aunque en ellos había jugado un papel destacado José Maria Gil Robles, cabeza visible del entorno juanista. 
heredero directo de Alfonso XIII ${ }^{90}$. Con ello se abría una fractura en la Familia Real Española que no se cierra hasta el 14 de mayo de $1977^{91}$. La proclamación de D. Juan Carlos como sucesor a título de rey, para cuando se cumplieran las previsiones sucesorias, fue contestada por una escueta declaración conjunta del Presidente de la República y el del Gobierno fechada en Buenos Aires en diciembre de $1969^{92}$.

El 16 de diciembre de 1970 fallece el II Presidente de la República en el exilio, Profesor Don Luis Jiménez de Asúa, en la capital argentina. Le sucede el Vicepresidente segundo de las Cortes D. José Maldonado, en rigurosa aplicación del Art. 74 de la Constitución ${ }^{93}$. Como era preceptivo, el profesor Sánchez Albornoz presenta la dimisión de su gobierno al nuevo Jefe del Estado ${ }^{94}$. El Presidente Maldonado le pide que continúe en el puesto pero D. Claudio se niega, por lo que encarga formar gobierno a Fernando Valera. ${ }^{95}$ Este presidirá el último de los nueve gobiernos republicanos en el exilio desde 1971 a $1977 .{ }^{96}$ Bajo su mandato tiene lugar la muerte de Franco y la proclamación del Príncipe Juan Carlos como Rey de España. ${ }^{97}$ Los dos Presidentes-Maldonado y Valera— son conscientes de la falta de apoyo de las potencias occidentales a la República en el exilio. En ese momento solo Méjico y Yugoslavia mantienen relaciones diplomáticas con el gobierno de la República siendo los únicos que reconocen su existencia. Como escribe Sonsoles Cabeza las potencias occidentales, negociando con Franco a partir de 1950 han hecho gala de la «laxitud de la conciencia democrática internacional» ${ }^{98}$.

\footnotetext{
${ }^{90}$ La propuesta de Franco fue realizada ante las Cortes Españolas y aceptada mayoritariamente por éstas el día 22 de julio de 1969 con el resultado de 491 votos a favor, 19 en contra ( de los monárquicos) y 9 abstenciones

${ }^{91}$ Este día Don Juan renuncia a sus derechos históricos y los traspasa a Don Juan Carlos.

${ }^{92}$ El texto íntegro en Del Valle: Op. Cit. Pág. $354-5$

${ }^{93}$ Había sido elegido para este cargo el 10 de marzo de 1968. A partir de esa fecha deja de actuar como Ministro de Justicia del Gobierno Sánchez Albornoz.

${ }^{94}$ En mayo de 1970 había obtenido el Premio Feltrinelli, considerado el Nóbel de los Historiadores.

${ }^{95}$ Republicano de largo recorrido. Aunque nacido en Las Madroñeras (Cáceres) pertenece al linaje cordobés de los Valeras cuyo personaje más conocido es el escritor egabrense y una de las mejores plumas de la literatura española.

${ }^{96}$ Como se ha señalado, el día 21 de junio de 1977, y tras la celebración de elecciones democráticas en España el día 15 de junio de dicho año, Maldonado y Valera hacen una última Declaración del Gobierno Republicano, desde París, anunciando la disolución del mismo y poniendo fin a las Instituciones Republicanas. El 30 de junio quedan disueltas las últimas Cortes del franquismo.

${ }^{97}$ Valera fue el último de los siete Jefes de Gobierno que tuvo la República en el exilio

${ }^{98}$ Véase Op. Cit. Pág.150.
} 


\section{RECUPERACIÓN DEMOCRÁTICA... Y RESTAURACIÓN MONÁRQUICA}

A la muerte de Franco se abre en España un trienio fundacional de un nuevo régimen. Se empieza a producir lo que el filósofo Julián Marías denominó la «devolución de España a los españoles». El joven Rey es consciente que no puede haber un franquismo sin Franco y pone en marcha una hábil maniobra, auténtico «encaje de bolillos» como la llama Gregorio Morán, para cambiar todas las bases de la política española y dar paso a otra bajo nuevos cimientos. La llamada Transición española cuenta para ello con tres «encajeros» de categoría: el Rey que por primera vez en la historia se pone al frente de una manifestación a favor de la democracia, Torcuato Fernández Miranda, el gran constructor, el hábil maestro autor de la Ley para la Reforma Política, magistral pieza de ingeniería político constitucional que permite acabar con el franquismo con la nota añadida de que sean los propios franquistas los que acaben con «su» régimen; y finalmente Adolfo Suárez, el encargado de asumir públicamente esta empresa y ejecutar y representar el libreto de Torcuato. El Rey será el «motor el cambio» como le denomina Areilza en la entrega de los Premios GODO 1976 y el verdadero factotum de este cambio. Es el empresario de la «obra» que le ha pedido a Fernández Miranda.

Se abre un proceso constitucional con carácter constituyente, aunque este término se ocultara celosamente en la convocatoria electoral del 15 de junio de 1977. El Rey sabe que el poder está en sus manos y en las del Ejército de Franco, amén de la Iglesia y los sectores financieros del país. La oposición lo más que puede, es hacerse presente en la calle, pero carece de auténticos resortes para cambiar la situación. Tiene lugar entonces una especie de «compromiso apócrifo» en el sentido schmittiano del término, en el que todos coinciden en una cosa: es necesario recuperar la democracia. Para ello la derecha española dará el visto bueno a la incorporación de la izquierda y su reconocimiento, dejándole una parcela de poder suficiente para afianzarse tras cuarenta años de destierro. A su vez la izquierda, que tiene conciencia de su escaso poder, acepta el juego, dando prueba de gran realismo político y asume el peaje de la restauración monárquica como precio obligado para la recuperación democrática. Quizás nadie como Santiago Carrillo supo expresar este compromiso. En el debate de totalidad al proyecto constitucional, al llegar al párrafo tercero del Art. $1^{\circ}$ que proclama solemnemente que «la forma política del Estado es la monarquía parlamentaria», el líder comunista reivindicó una vez más sus preferencias republicanas, lo mismo que su partido, pero advirtiendo que «reivindicar hoy la República, supone no obtener la República, y acabar con la democracia». Carrillo añade que mientras la mo- 
narquía respete la democracia, los comunistas respetaremos la monarquía. En sentido parecido se manifestó el PSOE, aunque Gómez Llorente, presentó un voto particular en nombre del grupo parlamentario a favor de la República que no dejaba de tener un valor puramente testimonial. Sometido a votación el párrafo tercero del Art. $1^{\circ}$ que consagraba la monarquía como forma de gobierno de España, el resultado no dejaba lugar a dudas. 23 votos a favor, 13 abstenciones y ningún voto en contra. Como afirmó el socialista Martín Toval en la Comisión: ser republicanos y votar hoy por la monarquía es salvar la institución. Tras cuarenta años, España recuperaba la democracia bajo el manto de la Corona. Se había dado un paso trascendental, no solo por lo que afectaba al tema siempre complicado de la forma de gobierno, y así lo advertía el maestro Pérez Serrano, sino también porque se abría paso a un proceso racionalizador del poder, como señaló el profesor Sánchez Agesta. Proceso puesto en marcha por un Rey que sabe que tiene que usar el poder recibido de Franco y las instituciones franquistas, precisamente para perder dicho poder, auto limitándose en el mismo, y que éste pasara al pueblo español. Se abría un periodo de la historia de España con un resultado muy positivo, que en gran parte fue posible por el talento y la generosidad de todos: republicanos, tanto del exilio como el interior, y monárquicos, con el Rey al frente. Era algo inédito en las costumbres políticas españolas.

Title

THE DREAM OF THE REPUBLICAN «RESTAURATION»

\section{Summary}

1. Introduction. 2. Institutional legality and legitimacy. 3. The schim of exile. 4. The international situation. 5. From Azaña to Maldonado. 6. Democratic recovery and... monarchist restoration.

\section{Resumen:}

El artículo describe y analiza la determinación de los republicanos en el exilio por mantener las instituciones democráticas, derrotadas en la Guerra Civil, en la creencia de un día a verlos de vuelta en España. Estas instituciones fueron legítimas y legales, de acuerdo con la Constitución de 1931. El sueño consistía en la restauración de la República en España. Su utopía terminó como un sueño frustrado. La recuperación de la democracia española en 1977 no trajo consigo la República, sino la restauración de la monarquía. 


\begin{abstract}
:
The article describes and analyzes the determination of the Republicans in exile to maintain the democratic institutions defeated in the civil war in the belief one day see them back in Spain. These institutions were legitimate and legal according to the Constitution of 1931. The dream consisted in restoring the Republic in Spain. Their utopia ended up as a frustrated dream. The recovery of Spanish democracy in 1977 did not mean the Republican, but the Monarchy restoration.
\end{abstract}

\title{
Palabras clave
}

Legitimidad. Legalidad. Sueño. Utopía. Monarquía. República

\section{Keywords:}

Legitimacy. Legality. Dream. Utopia. Monarchy. Republic. 